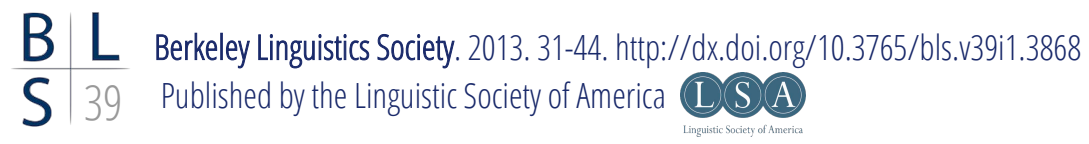

\title{
An Optimal Construction Morphology Approach to Augment Consonants in Kannada ${ }^{1}$
}

OANA A. DAVID

University of California, Berkeley

\section{Introduction}

The current paper provides an analysis of optimal consonant augment selection in the South Dravidian language Kannada, which is primarily spoken in the southeast Indian state of Karnataka. Augment consonants (hereafter ACs) ${ }^{2}$ in Kannada appear between the stem and suffix in certain phonotactic environments. Of all ACs, a subset is constrained in terms of the phonotactic environment in which they may occur. They apply to both derivational and inflectional morphology, particularly (but not exclusively) of nouns, the latter of which will be the sole focus of the current analysis. The nouns in (1) illustrate consonant augments in case morphology:

\begin{tabular}{|c|c|c|c|}
\hline (1) hudugi & 'girl' & $\begin{array}{l}\text { hudugi-l-inda } \\
\text { hudugi-y-inda } \\
\text { *hudugi-n-inda }\end{array}$ & 'from the girl \\
\hline huDuga & 'boy' & $\begin{array}{l}\text { huduga-n-a } \\
\text { *huduga-l-a }\end{array}$ & 'of the boy' \\
\hline$c a a$ & 'tea' & $\begin{array}{l}\text { caa-d-aage } \\
\text { *caa-n-aage }\end{array}$ & 'to the tea' \\
\hline
\end{tabular}

\footnotetext{
${ }^{1}$ I would like to thank audience members of BLS 39 who provided feedback, as well as Sharon Inkelas for her guidance throughout the development of this project from its inception. Additional thanks to Larry Hyman and Eve Sweetser for their helpful comments. I would also like to thank my consultant Vidwath.

2 Augment consonants are also known as epenthetic consonants. I retain the term 'augment' here in order to remain consistant with how it is referred to in Kannada grammars.
} 
Usually, the augments are considered an initial segment of the following suffix (Chisum 1975 and Hiremath 1961). However, I propose that they must be analyzed independently of inflectional or derivational suffixes, a practice which also results in a reduction of the amount of allomorphy in the language. I will provide a constraint-based semantic account of augment selection as I explain why the starred items in (1) are ungrammatical. The analysis is carried out in the framework of Optimal Construction Morphology (OCM) (Caballero and Inkelas, to appear, hereafter C\&I), and concludes that the emergence of augments in the first place is explained as an optimal word-formation mechanism. In Kannada, stems achieving word status via inflection cannot do so purely by bare suffixation, and augments are inserted so as to avoid vowel hiatus and to observe syllable coda requirements. However, in addition to these expected phonotactic constraints, there are also semantic motivations for augment selection. Namely, this paper argues that Kannada has come to take advantage of these existing mechanisms of phonological well-formedness in order to encode semantic features in what was once an empty morph. When comparing the augment inventory of Kannada and its morphological and semantic behavior with analogous morphemes in Malayalam, I also illustrate that a) a progression from an originally vacuous to a meaningful augment may have occurred fairly recently, and b) due to the availability of such a semantically contentful slot, the inventory of augments in Kannada has subsequently diversified relative to that in Malayalam. It did so in order to accommodate the rich semantic distinctions for which the augment is now used.

Like Kannada, Malayalam also observes the phenomenon of insertion of a glide in order to avoid vowel hiatus after suffixation: $-y$ - after a stem ending in front vowels /i, e/, and - $v$ - after those ending in back vowels /a, u/ (Mohanan 1986, Asher and Kumari 1997, Krishnamurti 2003). However, Kannada has taken this phenomenon beyond pure phonological necessity. Thus, I propose that while Kannada follows Dravidian languages in developing this augmental consonant to observe phonotactic constraints, it has come to use these augments as an encoding site for semantic information. The OCM framework, which has been applied by $\mathrm{C}$ \&I to explain how multiple exponence falls out naturally from wordhood building towards a target meaning, is extended in this paper to showing that Kannada empty morphs acquire functionality. Once they serve their purpose in advancing a stem towards wordhood, morphological items, as much as possible, take on a semantic value.

\section{$1 \quad$ Language Background}

The morphosyntactic facts about Kannada that are most relevant to this augmentinsertion phenomenon are the gender-agreement system and the nominal case inflection system. First, Kannada does not have systematic grammatical gendermarking on nouns, whereby each noun would fall in a grammatical gender catego- 


\section{Augment Consonants in Kannada}

ry (as is the case with Bantu and many European languages) but it has strategies for distinguishing animate from inanimate referents, and feminine from masculine human referents, a phenomenon called natural gender (Hiremath 1961) or 'rational' gender (Schiffman 1979). Among human referents, nouns underlyingly ending in $-a$ can either be masculine or feminine, and those ending in $-i$ are usually feminine. Verb agreement paradigms provide inflectional forms reflective of this natural gender:

\begin{tabular}{|c|c|c|c|}
\hline (2) a. & $\begin{array}{l}\text { aane-y-uu } \\
\text { elephant-AUG-CONJ } \\
\text { "The elephant and its }\end{array}$ & $\begin{array}{l}\text { maahuta-n-uu } \\
\text { rider-AUG-CONJ } \\
\text { rider came." }\end{array}$ & $\begin{array}{l}\text { band-ar-u } \\
\text { came-3pl.hum }\end{array}$ \\
\hline & $\begin{array}{l}\text { maahuta-n-uu } \\
\text { rider-AUG-CONJ }\end{array}$ & $\begin{array}{l}\text { aane-y-uu } \\
\text { elephant-AUG-CONJ }\end{array}$ & $\begin{array}{l}\text { band-av-u } \\
\text { came-3pl.non-hum }\end{array}$ \\
\hline
\end{tabular}

(from Sridhar 1990:246)

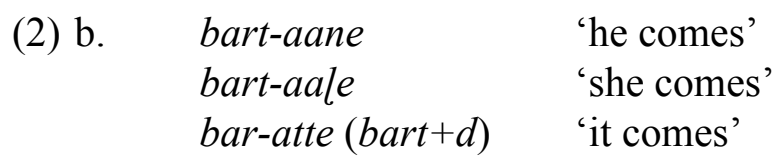

(from Schiffman 1979:56)

In $(2 \mathrm{a})$, the inflectional plural forms -ar-and $-\mathrm{a} v$ - are in agreement with the natural gender of 'elephant' (non-human) and 'rider' (human), respectively', but there is no morphology on the noun itself triggering this agreement other than the natural gender of the noun. In (2b) we see a verbal agreement paradigm for masculine, feminine and neuter (non-human) gender.

A second important aspect of Kannada is the role of the epenthetic vowel, as it contributes to word-formation, much as augments do. Uttered in isolation, all words must end in a vowel, and therefore those stems that are underlyingly consonant-final receive an epenthetic vowel. So, kaal- 'foot' becomes kaal-u, but $m a g u$ 'child' is underlyingly vowel-final. Augment insertion patterns and suffixation help illustrate that magu is a stem or word while kaal-u is a derived word, as in (3):

\footnotetext{
3 This data is in fact showing that agreement with coordinated nouns follows the most immediate noun; in this case, the human plural is used because the human-denoting noun is closest to the verb and the non-human plural is used when 'elephant' is closest to the verb.
} 
Oana A. David

(3) Case paradigms for Kannada nouns

\begin{tabular}{|c|c|c|c|c|c|}
\hline & 'man' & 'grass' & 'criticism' & 'girl' & 'boy' \\
\hline Nom. & gandas-u & hull-u & tikaa & hudugi & huduga \\
\hline Acc. & gandas-na & hul-na & tikaa-na & hudugi-na & huduga-na \\
\hline Abl. & gandas-in-inda & hull-in-inda & tikaa-d-inda & $\begin{array}{l}\text { hudugi-l-inda } \\
\text { hudugi-y-inda }\end{array}$ & huduga-n-inda \\
\hline Dat. & gandas-ge & hull-ige & tikaa-kke & hudugi-ge & huduga-ge \\
\hline Gen. & gandas-in-a & hull-in-a & tikaa-d-a & $\begin{array}{l}\text { hudugi-l-a } \\
\text { hudugi-y-a }\end{array}$ & huduga-n-a \\
\hline Loc. & gandas-in-alli & hull-in-alli & tikaa-d-alli & $\begin{array}{l}\text { hudugi-l-alli } \\
\text { hudugi-y-alli }\end{array}$ & huduga-n-alli \\
\hline & 'child' & 'one' & 'cow' & 'road' & 'foot' \\
\hline Nom. & magu & ond-u & $a s u$ & daari & kaal-u \\
\hline Acc. & magu-v-anna & ond-r-anna & asu-v-anna & daari-y-anna & kaal-anna \\
\hline Abl. & magu-v-inda & ond-r-inda & $a s u$-v-inda & daari-y-inda & kaal-in-inda \\
\hline Dat. & magu-v-ige & ond-r-ige & asu-v-ige & daari-(y)-(i)ge & kaal-ige \\
\hline Gen. & $\operatorname{mag} u-\boldsymbol{v}-a$ & ond-r-a & $a s u-v-i n-a$ & daari-y-a & kaal-in-a \\
\hline Loc. & magu-v-alli & ond-r-alli & asu-v-in-alli & daari-y-alli & kaal-in-alli \\
\hline
\end{tabular}

For instance, we know that hul 'grass' is underlyingly consonant-final because the $/ \mathrm{u} /$ is not retained when augments or other suffixes are added. On the other hand, asu 'cow' is a stem to which suffixes attach. The epenthetic vowel, thus, creates words out of stems, and this is the epenthetic vowel's only morphological function (Tirumalesh 1991). When case suffixes (which are all vowel-initial) combine with stems, the epenthetic vowel is not inserted, although it would be in some derivational processes where suffixes need to combine with words (as the gerunds in (4) below do).

ACs surface at other stem edges not involved in case suffixation, and therefore maintain a stable phonological basis uniformly throughout the language and are not a phenomenon exclusive to case morphology.

(4) Noun-noun derivation:

$\begin{array}{llll}\text { sere } & \text { 'custody' } & \text { sere-y-aalu } & \text { 'captive' } \\ \text { otte } & \text { 'pawn' } & \text { otte-y-aalu } & \text { 'hostage' }\end{array}$

Verb-gerund derivation:

$\begin{array}{llll}\text { hoog-u } u & \text { 'go' } & \text { hoog- } u \text {-v-ike } & \text { 'going', } \\ \text { ood- } u & \text { 'read' } & \text { ood-u-v-ike } & \text { reading' }\end{array}$

Here in (4) we see augments combining with words in two different forms: words that are underlyingly vowel-final and words that are vowel-final after epenthesis. As I proceed to discuss the distribution of ACs, their combinatorial properties will be elaborated beyond the basic $-y$ - and $-v$-glide augments. 


\section{Optimal Construction Morphology}

To show how Kannada takes advantage of phonological conditions in order to encode more semantics, I will use the framework of Optimal Construction Morphology developed by C\&I. My analysis shows that, assuming an OCM perspective, the semantically vacuous augment developed as a skipping-stone towards wordhood. It did not remain this way for long, instead developing as an encoding site for useful semantic information that the language otherwise has no mechanism for encoding in certain high-frequency paradigms (such as pronouns): namely, information pertaining to gender and animacy. Subsequently, this spread unevenly to other nouns in (only subsets of) the case paradigm. The approach in this paper depends in particular on one main premise of OCM: that "semantically vacuous layers of morphology can be optimal if and only if they make a contribution to structural well-formedness, e.g., by producing stems that meet phonological requirements or which advance a form along the wordhood scale (ibid:13)." This paper will use an OCM-based realizational approach to the building of casemarked nouns in Kannada while also considering the relative ranking of phonological and morphological constraints to stem-building. Furthermore, using the principles of realizational morphology (Stump 2001) and the concept of cophonologies applying at different levels (Anttila 2002), I also propose that before words are formed, constructions are selected from an internally organized constructional hierarchy of augments to incrementally build optimal structures.

\section{Kannada Consonant Augments}

\subsection{Description}

ACs found in Kannada nominal inflection are summarized in (5):

(5) Kannada augmental consonants

\begin{tabular}{|lllll|}
\hline & BASE & INPUT & SEMANTIC & THE FOLLOWING SUFFIX: \\
& ENDING: & CONSTRAINT: & CONSTRAINT: & \\
\hline$-v-$ & $\mathrm{u},-\mathrm{a}$ & word & -- & all cases, plural suffix, clitics \\
$-y-$ & $-\mathrm{i},-\mathrm{e}$ & word & --- & all cases, plural suffix, clitics \\
$-r-$ & $\mathrm{CC}$ & stem & --- & all cases, plural suffix, clitics \\
$-i n-$ & $\mathrm{C}$ & stem & --- & abl, loc, gen \\
$-n-$ & $\mathrm{V}$ & word & masculine & abl, loc, gen \\
$-l-$ & $\mathrm{V}$ & word & feminine & abl, loc, gen \\
$-d-$ & $\mathrm{V}$ & word & non-human & abl, loc, gen \\
\hline \multicolumn{2}{l}{ Nominative: ---} & Accusative: $-($ an $n a$ & Dative: $-(a a / i) g e$ \\
Ablative: $-i n d a$ & Locative: - alli & Genitive: $-a$
\end{tabular}

As (5) shows, four of the seven ACs have phonologically predictable behavior: - 
$v$ - comes after stems ending in back vowels, $-y$ - after stems ending in front vowels, and $-r$ - and -in- after stems ending in geminate consonants or consonants. By definition, morphological units ending in consonants are stems and those ending in vowels are words. For stems ending in consonants, the attachment of ACs does not achieve wordhood but simply brings the stem closer to wordhood. The wordhood scale, adapted from I\&C and based on previous scales from lexical phonology and morphology (Kiparsky 1982, Selkirk 1982, and others), is a scale that places roots, stems and words, in that order, along a scale of morphological development where each landmark point on the scale affords that item a special status in morphological and syntactic processes.

The ACs whose behavior is not phonologically predictable are the last three: $n-,-l-$, and $-d-$. First, along with $-i n$ - these have constraints as to what inflectional morphology they can occur with. Namely, they occur before a subset of case inflections: ablative, locative and genitive. Second, these three ACs, as I will show, are sensitive to the natural gender and humanness of the noun.

The distribution of augments, and the asymmetry they display across cases and across noun classes sets us up nicely for a meaning-driven OCM approach to word-building, which retains the assumptions of realizational approaches to morphology (Xu \& Aronoff 2011). Specifically, upon dipping into the lexicon in order to build the next layer of a stem, AC constructions make themselves available to fulfill some semantic or morphosyntactic property or properties that the target meaning may need represented. They do so while first respecting phonological constraints and while operating within their respective cophonological domains. While a $\mathrm{P}>>\mathrm{M}$ ordering of constraints is observed by default (appearing in the form of a stem shape and size constraint, vowel hiatus avoidance, and vowel feature conditioning on the stem), subsequent constraints on augment positioning and augment choice are determined by finer-grained cophonological structures, which I will explore in detail in the next section.

\subsection{Cophonologies and Constructions}

The availability of several phonologically different ACs for the same slot points to the reality of structured cophonologies in Kannada. Cophonologies are phonological functions holding between more and less schematic morphological constructions in a construction (Inkelas et al. 1994, Inkelas and Orgun 1995, Orgun 1996). Cophonologies arise from a theory that assumes a constructional organization of the lexicon (Booij 2010), which posits that the lexicon consists of a structured network of form-meaning pairings (constructions). Meaning compositionality is achieved through unification and constructions are related to each other via the principle of inheritance. A schematic construction sets the ordering and type constraints on morphology, while cophonologies instantiate particular subconstructions or constructs. Therefore, in Kannada there is a general noun for- 
mation morphological construction that unifies with some base form and creates a stem to which case suffixes can attach:

(6) General stem-building construction for Kannada nouns

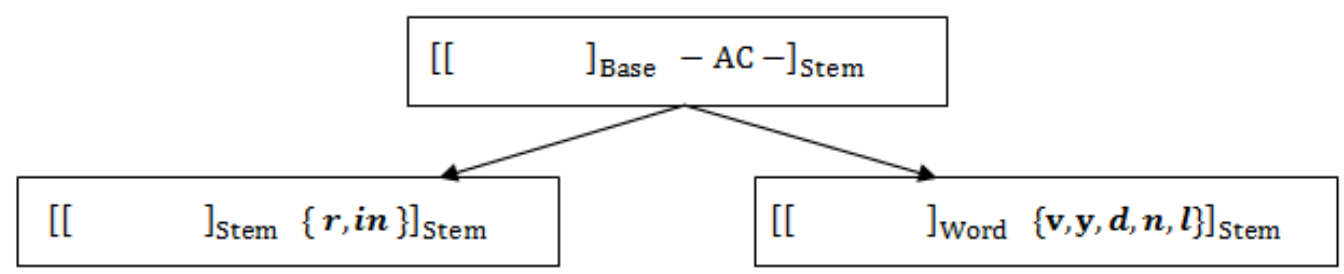

This in turn has two sub-constructions: one for which the base is necessarily a stem and one for which the base is necessarily a word. Each of these two subconstructions has several cophonologies available to them: $-r$ - and -in- for stem bases and $-v-,-d-,-n-,-l-$, and $-y$ - for word bases. Thus, in the realizational approach taken here, these are distinct cophonologies rather than distinct allomorphs. This distinction is a phonologically-motivated one: whether the base is a stem or a word makes a difference to the syllabic well-formedness of the resulting word given the phonological shape of the augment.

From these two basic AC sub-constructions, distinguished only by phonological constraints, cophonologies are selected according to three additional ordered criteria: 1) that the AC be limited to ablative, locative or genitive cases, 2) humaness, and 3) natural gender (feminine or masculine). Their hierarchical ordering in the constructional lattice is illustrated in (7):

(7) Constructional layers and their cophonologies

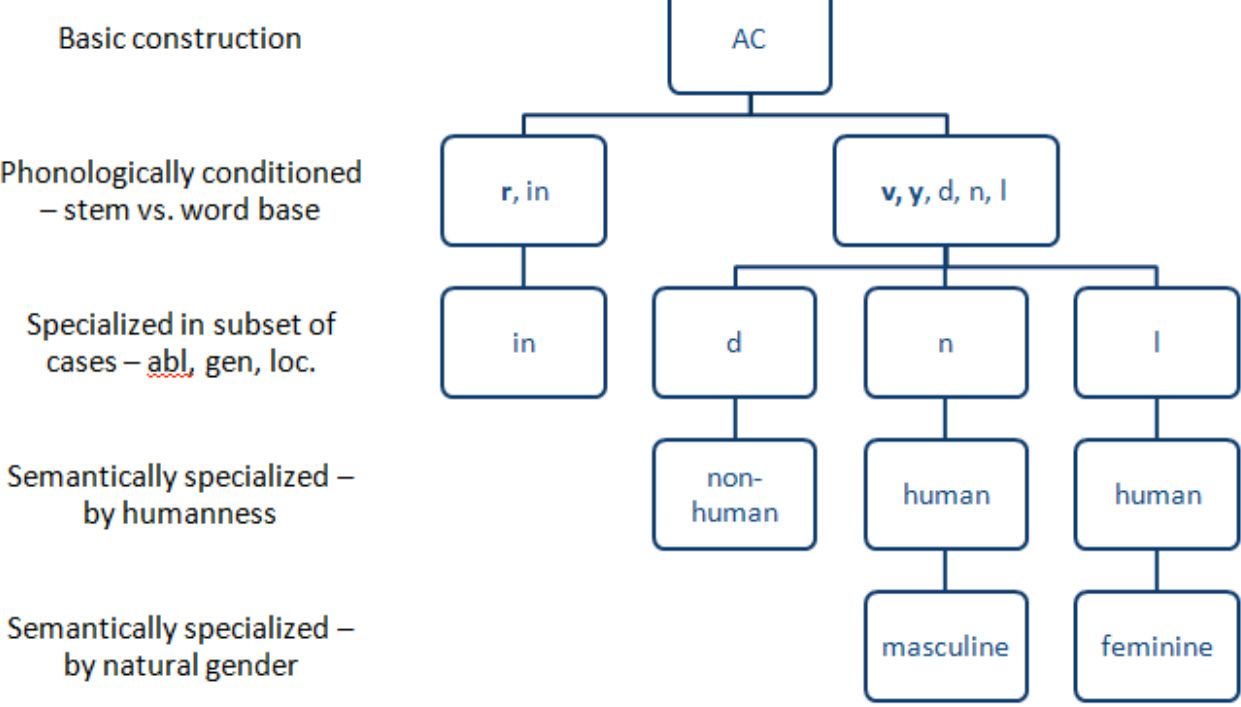




\section{Oana A. David}

According to the constructional lattice in (7), then, any given noun has at its disposal several paths when pursuing wordhood: the cophonology most specialized to it, and also every cophonology set above that level (i.e., more schematic and less specified for semantic, grammatical, or phonological constraints on the construct). For instance, looking at the paradigms in (3) we see that this generally works for nouns such as hudugi 'girl.' This noun can have two AC forms available to it, given that the case constraint is observed. It is a noun referring to a feminine referent, so the most informative $\mathrm{AC}$ is $-l-$; but it also has $-y$ - available to it, because, while not semantically specific, it is still upstream from - $l$ - in the constructional lattice, and unlike $-v$ - does not violate phonotactic constraints in matching vowel [-back] feature. On the other hand, $-d$ - and $-n$ - are not available because they are competing cophonologies at the same level, and these are specialized to other genders. Every noun in (3) can be run through the constructional lattice in (7), and they all respect this hierarchy. ${ }^{4}$

\subsection{Optimally-built Words}

In this section I will demonstrate, using OT tableaus in the OCM framework, how case-marked nouns in Kannada are built incrementally. Each tableau below represents one dip into the construction, whereby each constructional level treats each previous constructional level as the base. With each 'dip' there is a meaning target, and candidates are subject to only two ranked constraints: 1) that the resulting stem be formed with a stem or a word as a base, according to the requirements of a particular $\mathrm{AC}$, and 2 ) that the resulting construct be a stem. ${ }^{5}$

In (8), we are building the noun 'foot' with an ablative case suffix and with the meaning "from the foot." At this juncture in the constructional process the word does not mean anything beyond the core meaning of the root, but has only fulfilled one step in word-building. Candidates a, b, d, e, and $\mathrm{f}$ are eliminated because they require words as a base. Candidate $\mathrm{h}$ is eliminated because it has already reached wordhood and case cannot attach. There are three remaining candidates, c, g, and the identity candidate, that go on to round two.

Only one of the three remaining candidates crashes completely, and this is because it violates phonotactic constraints, which, according to $\mathrm{P}>>\mathrm{M}$, are always most highly ranked. It fails in both not having a CC-final base, as $-r$ - usually expects, and also in producing a liquid cluster. The identity candidate is not completely eliminated, but is less preferred by not poviding the speaker with the most

\footnotetext{
${ }^{4}$ Where logically possible alternative forms are not represented in (3), as they were for hu $u g i$, it is simply because they were not explicitly elicited from the speaker, and not because they are not possible. The current proposal predicts that they would be possible, (for instance, $-v$ - for $h u$ uga 'boy') and future additional elicitations should support this.

5 There are certainly more constraints involved, as evident in Figure 2, but for the sake of simplicity they are not included here. They may show up when breaking a tie between candidates, as in Figure 4.
} 


\section{Augment Consonants in Kannada}

specific construction available to him, which is that provided by candidate a.

(8) Building FOOT-ABL, first dip

\begin{tabular}{|r|l|l||c|c|}
\hline & $\begin{array}{l}\text { kaal } \\
\text { 'foot' }\end{array}$ & M: FOOT & $\begin{array}{c}\text { STEM-AS- } \\
\text { BASE }\end{array}$ & BE STEM \\
\hline a. & - -v- & kaal]-v]- & $* !$ & \\
\hline b. & - -y- & kaal]-y]- & $* !$ & \\
\hline c. & - in- & kaal]-in]- & & \\
\hline d. & $-1-$ & kaal]-l]- & $* !$ & \\
\hline e. & - -n- & kaal]-n]- & $* !$ & \\
\hline f. & - d- & kaal]-d]- & $* !$ & \\
\hline g. & - r- & kaal]-r]- & & \\
\hline h. & $-\mathrm{u}$ & kaal]-u] & & $* !$ \\
\hline i. & & kaal]- & & \\
\hline
\end{tabular}

(9) Building FOOT-ABL, second dip

\begin{tabular}{|r|l|l||c|c|c|}
\hline & $\begin{array}{l}\text { kaal } \\
\text { 'foot' }\end{array}$ & M: FOOT-ABL. & $*$ LR STEM-CC & OBL.-CASE & MAX-IO \\
\hline b. & -in]-inda & kaal]-in]-inda & & & $*$ \\
\hline c. & -r]-inda & kaal]-r]-inda & $* !$ & & \\
\hline
\end{tabular}

The tableaus in (10) and (11) provide a second example, this time with hudugi 'girl.'

(10) Building girl-gen, first dip

\begin{tabular}{|c|c|c|c|c|c|}
\hline & $\begin{array}{l}\text { hudugi } \\
\text { 'girl' }\end{array}$ & M: GIRL & $\begin{array}{c}\text { STEM- } \\
{[\alpha \text { back }]}\end{array}$ & $\begin{array}{l}\text { WORD- } \\
\text { AS-BASE }\end{array}$ & BE-STEM \\
\hline a. & -v]- & huDugi\}-v]- & $* !$ & & \\
\hline $\mathrm{b}$. & $-y]-$ & huDugi\}-y]- & & & \\
\hline c. & $-d]-$ & huDugi\}-d]- & & & \\
\hline $\mathrm{d}$. & $-1]-$ & huDugi\}-1]- & & & \\
\hline $\mathbb{0} \mathrm{e}$. & $-n]-$ & huDugi\}-n]- & & & \\
\hline f. & -in]- & huDugi\}-in]- & & * & \\
\hline g. & $-r]-$ & huDugi\}-r]- & & * & \\
\hline h. & $-\mathrm{u}\}$ & huDugi\}-u\} & & & * \\
\hline i. & & huDugi\} & & & \\
\hline
\end{tabular}

Here there is a local competition between $\mathrm{a}$ and $\mathrm{b}$ relative to the vowel feature matching constraint. Otherwise, in addition to the winner $b$, there are multiple other winners, including the identity candidate, which together are the sole candi-

${ }^{6}$ Curly brackets represent word edges, while square brackets represent stem edges. 


\section{Oana A. David}

dates that make it to the second dip:

(11) Building girl-GEN, second dip

\begin{tabular}{|c|c|c|c|c|c|c|}
\hline & $\begin{array}{l}\text { hudugi } \\
\text { 'girl' }\end{array}$ & M: GIRL-GEN & $\begin{array}{l}\text { *VOWEL- } \\
\text { HIATUS }\end{array}$ & $\begin{array}{l}\text { MATCH- } \\
\text { GENDER }\end{array}$ & $\begin{array}{l}\text { MATCH- } \\
\text { HMN }\end{array}$ & $\begin{array}{l}\text { OBL- } \\
\text { CASE }\end{array}$ \\
\hline$a$ & $-y]-a^{7}$ & huDugi\}-y]-a & & & & $*$ \\
\hline b. & $-d]-a$ & huDugi\}-d]-a & & & $* !$ & \\
\hline $\mathrm{c}$. & $-1]-\mathrm{a}$ & huDugi\}-1]-a & & & & \\
\hline d. & $-n]-a$ & huDugi\}-n]-a & & $* !$ & & \\
\hline e. & & huDugi\}-a & $* !$ & & & \\
\hline
\end{tabular}

The identity candidate $\mathrm{e}$ is eliminated due to violating a highly ranked $\mathrm{P}$ constraint. The remaining constraints are semantic, and they are ranked in an order matching that of the constructional lattice in (10): gender distinctions are most specific, followed by humanness, and lastly the case subset constraint. Candidate $\mathrm{b}$ crashes by failing to match humanness, while $\mathrm{d}$ crashes by failing to match gender. The last remaining candidates, a and c, are both available to the speaker, although $\mathrm{c}$ is more preferred due not violating any constraints. Candidate a survives because $-v$ - is available upstream in the constructional lattice, and thus continues to be a viable, albeit less semantically informative variant.

\section{$4 \quad$ Implications}

The questions must now be asked: why these particular alloconstructions cophonologies and not others? And why should such diversity in ACs be available in Kannada? To address these questions, I provide a comparison with an analogous phenomenon in a closely-related language, Malayalam. As part of its AC inventory, Malayalam has only $-v-,-y$ - and -in- (12).

(12) Augmental consonants in Malayalam (data from Asher \& Kumari 1997:192): ${ }^{8}$

$\begin{array}{llll}\begin{array}{l}\text { kuru } \\ \text { puu } \\ \text { foottoo }\end{array} & \begin{array}{l}\text { 'seed' } \\ \text { 'flower' }\end{array} & \begin{array}{l}\text { kuru-v-um } \\ \text { puu-v-um } \\ \text { foottoo-v-il }\end{array} & \begin{array}{l}\text { 'also the seed' } \\ \text { 'also the flower' } \\ \text { 'in the photo' }\end{array} \\ k \text { kutti } & \text { 'child' } & k u t t i-\boldsymbol{y} \text {-um } & \text { 'also the child' }\end{array}$

7 The most specific semantic specifications for each of the candidate formants are: $-y$ - no semantics $\quad-d-\quad$ non-human

$-l-\quad$ human feminine $\quad-n-\quad$ human masculine

8 In Malayalam - $n$ - and - $l$ - are available as gender markers, and are lexicalized as part of the noun in some cases. For instance, the pre-case stem for 'son' is makan and for daughter is makal. However, these do not appear as ACs. 


$\begin{array}{llll}\text { tii } & \text { 'fire' } & \text { tii-y-il } & \text { 'in the fire' } \\ \text { ivite } & \text { 'here' } & \text { ivite-y-um } & \text { 'also here' } \\ \text { caaya } & \text { 'tea' } & \text { caaya-y-um } & \text { 'also the tea' } \\ \text { viit } & \text { 'house' } & \text { viit-in-re } & \text { 'of the house' } \\ \text { coor } & \text { 'rice' } & \text { coor-in-re } & \text { 'of the rice' }\end{array}$

The phonotactic constraints on their distribution are nearly identical to those in Kannada. There is a difference in the stem vowel between the two languages, with $-v$ - being restricted to /u/, probably on the basis of shared labiality, while in Kannada -v- follows all back vowels. However, as (13) summarizes, Kannada has a much larger inventory of ACs, one that includes some ACs with identical phonotactic constraints.

(13) Comparison of Malayalam and Kannada AC inventories

\begin{tabular}{ccc|ccc}
\hline \multicolumn{3}{c|}{$\begin{array}{c}\text { Malayalam } \\
\text { Inventory }\end{array}$} & \multicolumn{3}{c}{$\begin{array}{c}\text { Kannada } \\
\text { Equivalent }\end{array}$} \\
\hline AFTER & AC & BASE & AFTER & AC & BASE \\
\hline $\mathrm{u}-$ & $-\mathrm{v}-$ & stem & u-, a- & $-\mathrm{v}-$ & word \\
$\mathrm{a}-, \mathrm{i}-, \mathrm{e}-$ & $-\mathrm{y}-$ & stem & i-, e- & $-\mathrm{y}-$ & word \\
$\mathrm{C}$ & $-\mathrm{in}-$ & stem & $\mathrm{C}$ & $-\mathrm{in}-$ & stem \\
& & & $\mathrm{CC}$ & $-\mathrm{r}-$ & stem \\
& & & $\mathrm{V}$ & $-\mathrm{l}-$ & word \\
& & & $\mathrm{V}$ & $-\mathrm{n}-$ & word \\
& & & $\mathrm{V}$ & $-\mathrm{d}-$ & word
\end{tabular}

On the basis of this comparison, I propose that cross-linguistically in the linguistic region, ACs started as empty morphs but specialized as contentful (non-empty) morphs in Kannada. When an empty morph acquires meaning, it becomes more like a genuine construction: a form-meaning pairing with conventional use as well as unification constraints on combining with other constructions (such as casemarking) (Goldberg 1995, Booij 2010). To aid in its endeavor to become a bona fide construction, the noun formation construction recruited phonological forms from morphemes in the verb agreement paradigm and from gender marking present elsewhere in the language. We saw, for instance, in example (2b) that verb agreement takes an -al-suffix for agreement with nouns denoting feminine entities, and -an-for agreement with nouns denoting masculine entities. Furthermore, the pronominal paradigm in Kannada is revealing of the origins of these ACs as well: 
Oana A. David

(14) Pronominal paradigm in Kannada

\begin{tabular}{|lllll|}
\hline & $1 \mathrm{sg}$ & $1 \mathrm{pl}$ & $2 \mathrm{sg}$ & $2 \mathrm{pl}$ \\
\hline Nom & $n$-aan-u & $n$-aa-v-u & $n$-iin-u & $n$-ii-v-u \\
Acc & $n$-ann-ann-u & $n$-amm-ann-u & $n$-inn-ann-u & $n$-i-mm-ann-u \\
Abl & $n$-ann-inda & $n$-amm-inda & $n$-inn-inda & $n$-i-mm-inda \\
Dat & $n$-an-age & $n$-am-age & $n$-in-age & $n$-i-m-age \\
Gen & $n$-ann-a & $n$-amm-a & $n$-inn- $a$ & $n$-i-mm-a \\
Loc & $n$-ann-alli & $n$-amm-alli & $n$-inn-alli & $n$-i-mm-alli \\
\hline
\end{tabular}

\begin{tabular}{|c|c|c|c|c|c|}
\hline & $3 \mathrm{sg} \cdot \mathrm{masc}$ & 3sg.fem & $3 \mathrm{pl}(\mathrm{m}+\mathrm{f})$ & 3sg.neut & 3pl.neut \\
\hline Nom & $a-v-a n-u$ & $a-v-a l-u$ & $a-v-a r-u$ & $a-d-u$ & $-v-u$ \\
\hline Acc & $a-v-a$ nn- $u^{9}$ & $a-v-a l-a n n-u$ & $a-v-a r-a n n-u$ & a-d-anna & \\
\hline $\mathrm{Abl}$ & $a-v-a n-i n d a$ & $a-v-a l-i n d a$ & $a-v-a r-i n d a$ & $a-d-a r-i n d a$ & \\
\hline Dat & $a$-v-an-ige & $a$-v-al-ige & $a$-v-ar-ige & a-d-akke & \\
\hline Gen & $a-v-a n-a$ & $a-v-a l-a$ & $a-v-a r-a$ & $a-d-a r-a$ & \\
\hline Loc & $a-v-a n-a l l i$ & $a-v-a l-a l l i$ & $a-v$-ar-alli & $a-d-a r-a l l i$ & \\
\hline
\end{tabular}

Although lexicalized, these forms preserve some trace of agreement on the basis of natural gender and humanness, with $-n$ - reserved for 3 sg masculine pronouns, $-l$ - for $3 \mathrm{sg}$ feminine pronouns, and $-d$ - for $3 \mathrm{sg}$ neuter pronouns. The masculine $-n-$ is also the default human marker, as it applies to all 1sg and 2 sg pronouns.

\section{Conclusions}

Kannada exhibits a structured noun formation constructional lattice with different, increasingly specialized cophonologies. The latter are evident in the schematic stem-forming construction provided by ACs, and are sensitive to semantic features: namely, the humanness and natural gender of the noun. Although ACs appear elsewhere in noun formation, it is in case morphology that the augmentinsertion function is most developed in the language, and most specialized according to semantic and grammatical characteristics. The augments $-n-,-l-$ and $-d-$ seem to be introduced into case morphology from gender- and humannessmarking morphs borrowed from verb agreement and from pronouns. These surface only in a subset of case inflections: ablative, genitive, and locative. It is unclear why these cophonologies should respond a) only to a subset of cases, and b) why these particular ones. To tentatively address (a): it may be that we are seeing an incomplete intermediate stage of spread throughout the case inflection paradigm. To tentatively address (b): there are other studies arguing that morphological syncretism among cases occurs when those cases share some semantics (cf. Lakoff and Johnson 1999 for comitative-instrumental case syncretism, for instance), and some form of specialized case syncretism may be occurring here as

9 The accusative here is still -ann, but sandhi rules apply. 
well, one in which ablative, genitive and locative cases share some semantic or pragmatic motivation.

Finally, the combined top-down and bottom-up approach provided by the OCM framework has enabled us to incorporate both phonological and semantic constraints into one optimal word-building process. Further, by allowing multiple sequential 'dips' into the construction for further additions to the stem, it was also possible to have multiple winning candidates, thus also more accurately reflecting same- and across-dialect variation in grammatical forms as well as the simultaneous availability of multiple forms in Kannada. We saw that the extent of variability available for any given noun is subject to the strictly-structured constructional lattice with its available cophonologies according to semantic constraints.

\section{References}

Acharya, A. Sriramana. 1971. Tiptur Kannada. Linguistic Survey of India Series 8. Poona: Deccan College.

Anttila, Arto. 2002. Morphologically Conditioned Phonological Alternations. Natural Language and Linguistic Theory 20:1-42.

Asher, Ronald E., \& T. C. Kumari. 1997. Malayalam. Psychology Press.

Booij, G. 2010. Construction Morphology. Oxford University Press.

Bright, William. 1970. Phonological Rules in Literary and Colloquial Kannada. Journal of the American Oriental Society 90(1): 140-144.

Caballero, G. \& Sharon Inkelas. to appear. Word Construction: Tracing an optimal path through the lexicon. To appear in a special issue of Morphology, guest-edited by Jochen Trommer.

Chisum, G. L. 1975. Systematic phonology of the Kannada noun. In, H. F. Schiffman and C. M. Eastman, eds., Dravidian Phonological Systems. University of Washington.

Hiremath, R. C. 1961. The Structure of Kannada. Karnataka University.

Inkelas, Sharon and Cemil O. Orgun. 1995. Level ordering and economy in the lexical phonology of Turkish. Language 71(4): 763-793.

Inkelas, S., C. O. Orgun and C. Zoll. 1994. The Big Bang: Subregularities as Cogrammars. Presented at the Trilateral Phonology Weekend, University of California, Santa Cruz.

Kiparsky, Paul. 1982. Word-formation and the lexicon. In 1982 Mid-America linguistics conference papers, ed. by Frances Ingemann. Lawrence, Kan: University of Kansas.

Krishnamurti, B. 2003. The Dravidian Languages. Cambridge University Press.

Lakoff, George, and Mark Johnson. 1999. Philosophy in the Flesh: The Embodied Mind and its Challenge to Western Thought. Basic Books.

Nayak, H. M. 1967. Kannada: Literary and Colloquial. A Study of the Two Styles. Mysore: Rao and Raghavan. 
Orgun, Cemil O. 1993. Sign-based Morphology and Phonology. Doctoral dissertation, University of California.

Selkirk, Elisabeth. 1982. The Syntax of Words. Cambridge, MA: MIT Press.

Schiffman, H. 1979. A Reference Grammar of Spoken Kannada. Washington DC: Division of International Education.

Sridhar, S. N. 1990. Kannada. London, New York: Routldege.

Stump, Gregory. 2001. Inflectional Morphology: A Theory of Paradigm Structure. Cambridge: Cambridge University Press.

Tirumalesh, K.V. 1991. The Dravidian Enunciative Vowel and its Impact on the Syllable Structure of Kannada. Indian Linguistics 50:148-155.

Xu, Z., \& Aronoff, M. 2011. A Realization Optimality Theory Approach to Blocking and Extended Morphological Exponence. Journal of Linguistics, 47(03): 673-707.

Oana David

University of California, Berkeley

Department of Linguistics

1203 Dwinelle Hall

Berkeley, CA 94720-2650

oanadavid@berkeley.edu 